\title{
Grain Refinement after Various Thermo-Mechanical Treatments in AZ80 and ZK60 Magnesium Alloys
}

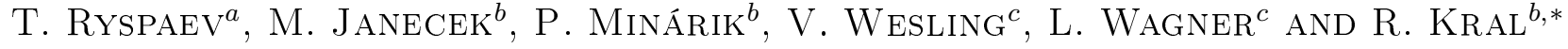 \\ ${ }^{a}$ Kyrgyz State Technical University, 66 Mira av., 72004, Bishkek, Kyrgyzstan \\ ${ }^{b}$ Charles University, Ke Karlovu 5, 121 16, Prague, Czech Republic \\ ${ }^{c}$ Clausthal University of Technology, Agricolastr. 6, 38678, Clausthal-Zellerfeld, Germany
}

The effect of thermal processing prior to severe plastic deformation by extrusion and swaging on grain refinement in ZK60 and AZ80 alloys was studied. The alloys received in direct-chill cast condition were homogenized at $415^{\circ} \mathrm{C}$ and annealed (over-aged) at temperatures from 200 to $380^{\circ} \mathrm{C}$. Both the direct-hill cast and over-aged conditions were extruded at $T=300^{\circ} \mathrm{C}$ using an extrusion ratio of $\mathrm{ER}=19$. Hot extrusion resulted in substantial grain refinement in both cases, the effect being stronger in the over-aged material. The extruded bars were severe plastically deformed at $250{ }^{\circ} \mathrm{C}$ by swaging. Swaging refined further the grain size depending on the deformation ratio (number of passes). At optimal processing conditions the grain size was $450 \mathrm{~nm}$ and $570 \mathrm{~nm}$ for the AZ80 and ZK60 alloys, respectively.

PACS: $81.40 . \mathrm{Gh}, 81.07 . \mathrm{Bc}$

\section{Introduction}

The grain refinement presents a particularly attractive strengthening mechanism since both yield stress and tensile ductility can be enhanced. The increase in yield stress often leads to a concomitant enhancement in high-cycle fatigue strength while the increase in tensile ductility can lengthen the fatigue life in the low-cycle fatigue. Over the last two decades there has been remarkable interest in investigation of materials with ultrafine grain (UFG) sizes and many new technologies of production of UFG materials by severe plastic deformation (SPD) have been developed, like equal channel angular pressing (ECAP), accumulative roll-bonding or high pressure torsion [1, 2]. Besides these techniques there are also rather conventional methods such as hydrostatic extrusion or swaging which may also lead to significant grain refinements $[3,4]$.

Although these methods, especially ECAP, led to an UFG structure in many materials, including wide spectrum of magnesium alloys [5], the effect of secondary phases that can substantially suppress the dynamic recrystallization (DRX) has not been systematically studied, yet. The composition and distribution of particles of secondary phases can be influenced by thermal processing, therefore the aim of this work was to study the effect of thermal processing prior to SPD by extrusion and swaging on grain refinement in ZK60 and AZ80 alloys that are currently used in the industrial applications. In these alloys, it is possible to achieve both the fine-grained structure and the superplastic behavior depending on the microstructure, namely the morphology of the large particles of $\beta$-phase and fine particles of stable intermetallic phases.

\footnotetext{
* corresponding author; e-mail: rkral@met.mff.cuni.cz
}

\section{Material and experimental procedure}

The investigated AZ80 alloy belongs to the ternary $\mathrm{Mg}-\mathrm{Al}-\mathrm{Zn}$ system, but $\mathrm{Mn}$ and $\mathrm{Zr}$ are also present, the actual weight concentrations being $8.60 \% \mathrm{Al}, 1.14 \% \mathrm{Zn}$, $0.21 \% \mathrm{Mn}$ and $0.03 \% \mathrm{Zr}$. ZK60 belongs to the ternary $\mathrm{Mg}-\mathrm{Zn}-\mathrm{Zr}$ system with actual concentrations $6.75 \% \mathrm{Zn}$ and $0.53 \% \mathrm{Zr}$. The alloys were received in direct-chill (DC) cast condition in the form of bars of the initial diameter of $75 \mathrm{~mm}$.

In the processing route "EX1", the as-cast rods were extruded at $300{ }^{\circ} \mathrm{C}$ to $16 \mathrm{~mm}$ final diameter corresponding to extrusion ratio $\mathrm{ER}=19$ using a $6300 \mathrm{kN}$ direct extrusion press. After the hot extrusion a part of the rods was swaged at an initial temperature of $250^{\circ} \mathrm{C}$ to three different diameters, namely $11 \mathrm{~mm}, 8.5 \mathrm{~mm}$ and $4.5 \mathrm{~mm}$ using a 4 -hammer rotary swaging system. The corresponding logarithmic deformation degree was $\varphi=0.8,1.3$, and 2.5 , respectively.

The processing route "EX2" involved homogenization of the as-cast rods at $415^{\circ} \mathrm{C}$ for $20 \mathrm{~h}$, followed by over-aging at temperatures 200 to $380^{\circ} \mathrm{C}$. The selected homogenization treatment was found to be sufficient for both AZ80 and ZK60 alloys [6, 7]. During homogenization the rods were sealed into an aluminium foil in order to prevent oxidation. Subsequently the rods were swaged at an initial temperature of $250^{\circ} \mathrm{C}$ to the same deformation degree as in the first route.

The microstructures of the different conditions were investigated using optical microscopy, scanning electron microscopy and energy-dispersive $\mathrm{X}$-ray spectroscopy.

\section{Results and discussion}

Both investigated alloys exhibit a very large grain size in the as-cast state, $\approx 80 \mu \mathrm{m}$ and $\approx 110 \mu \mathrm{m}$ for $\mathrm{AZ} 80$ and ZK60, respectively. The grain structure is presented in Fig. 1a and b, respectively. An extensive investigation 
has been performed to identify the optimal conditions of over-aging of the material before further processing by extrusion and swaging. Both alloys were annealed at temperatures ranging from 200 to $380^{\circ} \mathrm{C}$ for the time periods ranging from 2 to $16 \mathrm{~h}$. The optimal over-aging treatment in the terms of the highest grain refinement after subsequent processing by extrusion and swaging was identified to be $300^{\circ} \mathrm{C}$ for $10 \mathrm{~h}$ in both alloys.

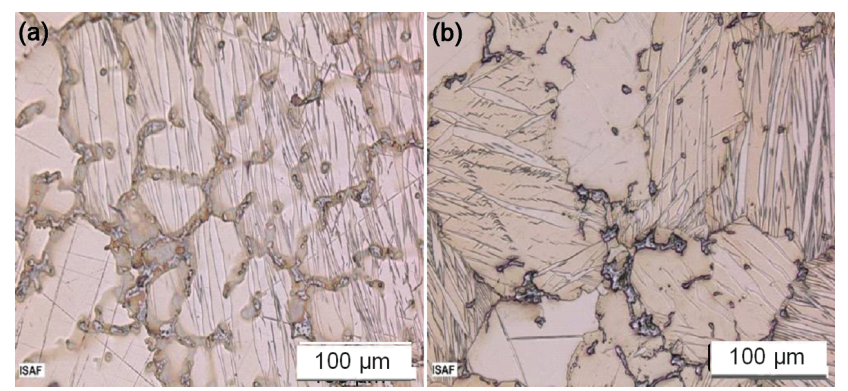

Fig. 1. Cast structure of the magnesium alloys: (a) AZ80, (b) ZK60.

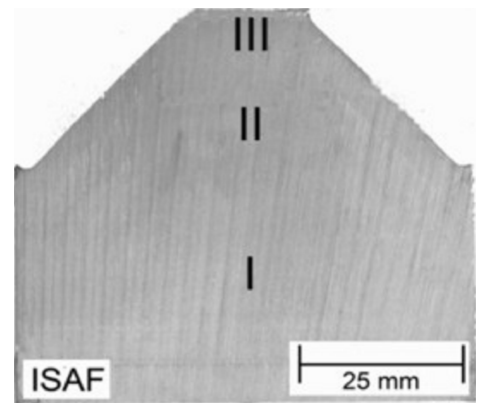

Fig. 2. Denotation of individual positions in the rest of a magnesium alloy from the extrusion press.

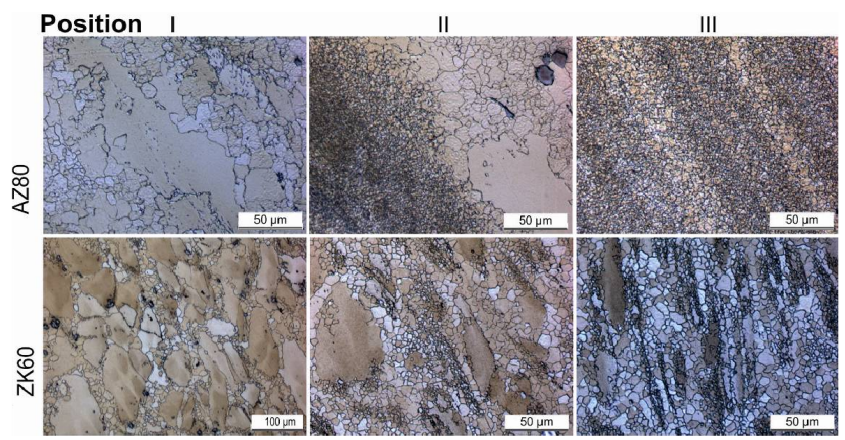

Fig. 3. Dependence of microstructure on the position in the rest of extruded alloy.

In order to evaluate the evolution of microstructure during the extrusion, the rest of the alloy from the extrusion press was cut into two pieces and the microstructure was investigated at three different positions as indicated in Fig. 2 as I, II and III. The flow of the material was clearly visible in the cross-section area. From light micrographs of a material with pre-treatment (route EX2) in Fig. 3 it is obvious that at the position I both alloys remain undeformed whereas at position II there are large grains surrounded by fine grains formed in shear bands. The increasing deformation results in further recrystallization and finally at position III the material exhibits a fine-grained structure with only very few larger grains elongated in the extrusion direction.

A substantial grain refinement was observed in both alloys after pre-treatment (EX2) at position III. In case of ZK60 we assume that the fine-grained microstructure is induced by zirconium and/or zinc rich particles of secondary phases that have been formed during over-aging and which act as nuclei during DRX. The presence of ultrafine globular $\mathrm{Zn}_{2} \mathrm{Zr}$ und lamellar $\mathrm{Mg}_{2} \mathrm{Zn}$ phases in ZK60 has been reported by other authors [8, 9]. In AZ80, since the $\mathrm{Zr}$ content is very low, we assume that coarser $\mathrm{Mg}_{17} \mathrm{Al}_{12}$ and $\mathrm{Mg}_{7} \mathrm{Zn}_{3}$ particles [10] play the main role.

Further grain refinement in the hot-extruded AZ80 and ZK60 alloys was achieved by swaging. The light micrographs of material after swaging are presented in Fig. 4 (p. 624) for both processing routes - EX2/EX1 i.e. with/ without thermal pre-treatment. SEM micrographs of EX2/swaged AZ80 and ZK60 with deformation degree $\varphi=2.5$ are shown in Fig. 5 .

The grain refinement during swaging depends strongly on the degree of deformation, and also the initial EX1/ EX2 state of the rods before swaging plays a very important role, see Fig. 6. In case of material with pre-treatment (EX2), the swaging with logarithmic deformation degree $\varphi$ ranging from 0.8 to 2.5 resulted in grain size ranging from $\approx 2 \mu \mathrm{m}$ to $\approx 450 \mathrm{~nm}$ in both $\mathrm{AZ} 80$ and ZK60 alloys, i.e. grain sizes by factor $\approx 2$ smaller than the values reported in the literature for the same alloys homogenized (but not over-aged) before extrusion $[11,12]$. On contrary, in the case of extrusion directly from the as-cast material (EX1) in the present case the grain sizes of $\approx 4 \mu \mathrm{m}$ are by factor $\approx 2$ larger than material homogenized before extrusion in $[11,12]$.

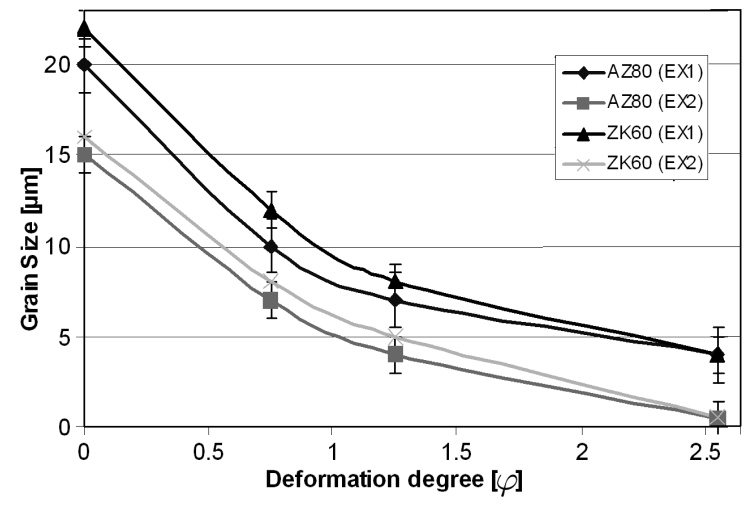

Fig. 6. Influence of the deformation degree $\varphi$ on the grain size alloys AZ80 and ZK60. 


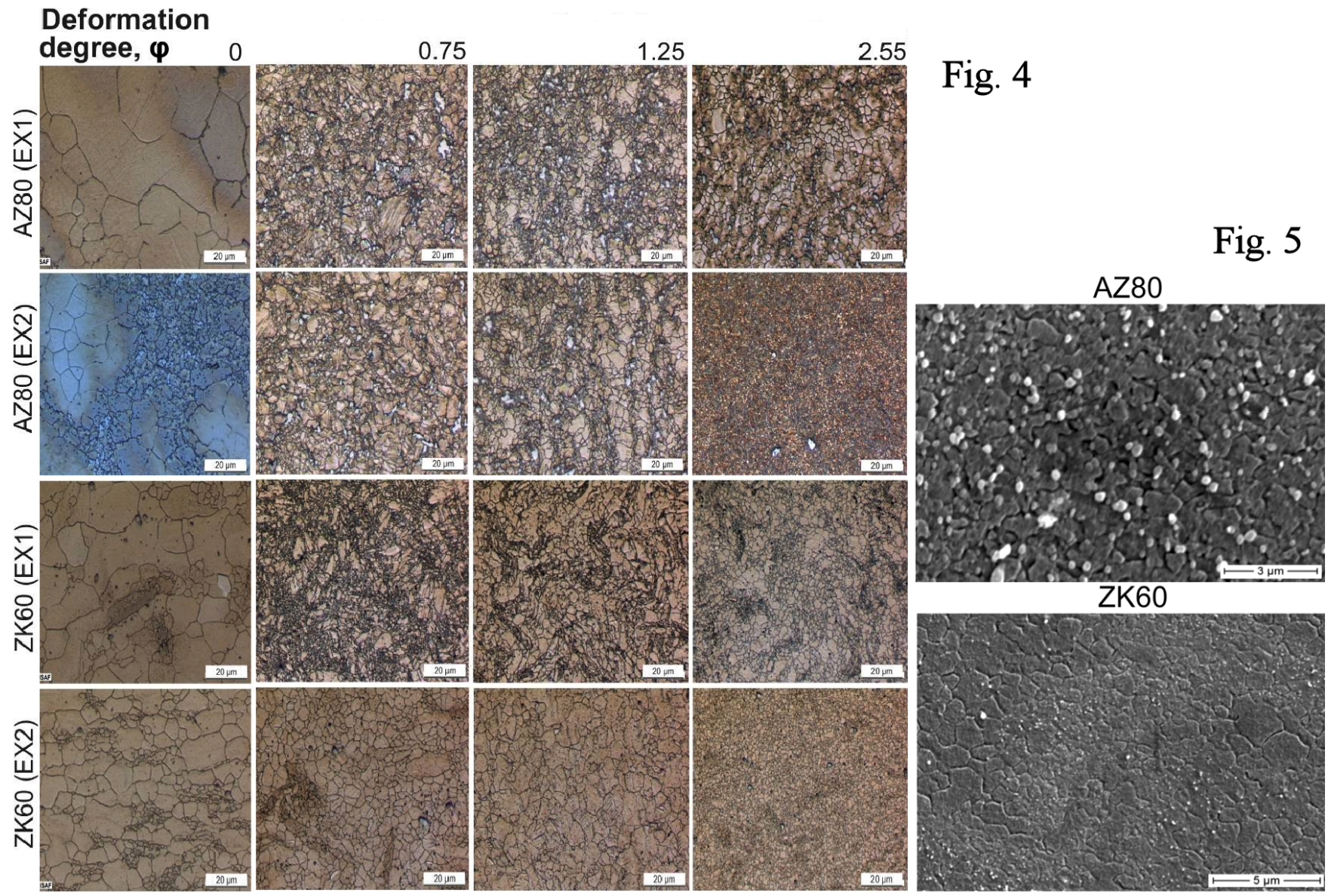

Fig. 4. Optical micrographs of the microstructures of swaged AZ80 and ZK60 depending on deformation degree: EX1 extruded as cast, EX2 extruded with pre-heat treating.

Fig. 5. SEM micrographs of swaged AZ80 and ZK60 with deformation degree $\varphi=2.5$.

\section{Conclusions}

Substantial grain refinement was observed after hot extrusion both in DC cast and over-aged material, with a stronger effect in the over-aged material. Further grain refinement was observed after swaging depending on the deformation degree. At optimal processing conditions the grain size was $450 \mathrm{~nm}$ a $570 \mathrm{~nm}$ for the AZ80 and ZK60 alloys, respectively, i.e. by factor $\approx 2$ smaller than the grain size reported in the literature for the same material without over-ageing before hot extrusion.

\section{Acknowledgments}

This work was financially supported by DAAD-AVCR under the project MEB101106. Partial financial support by GACR, grant no. 109/09/0482 is also acknowledged.

\section{References}

[1] Investigations and Applications of Severe Plastic Deformation, Eds. T.C. Lowe, R.Z. Valiev, Kluwer, Dordrecht 2000.

[2] Z. Horita, K. Ohashi, T. Fujita, K. Kaneko, T.G. Langdon, Adv. Mater. 17, 1599 (2005).

[3] L. Rong, Z. Nie, T. Zuo, Mater. Sci. Eng. A 464, 28 (2007).
[4] B. Katavic, Z. Odanovic, M. Burzic, Mater. Sci. Eng. A 492, 337 (2008).

[5] J. Swiostek, J. Bohlen, D. Letzig, K.U. Kainer, $M a g-$ nesium - Proc. 6th Int. Conf. on Magnesium Alloys and Their Applications, Ed. K.U. Kainer, Wiley-VCH, Weinheim, Germany 2004, p. 278.

[6] Y.Q. Yang, Z.M. Zhang, B.C. Li, Mater. Sci. Forum 686, 6 (2010).

[7] R. Kral, P. Lukac, P. Minarik, B. Smola, S. Danis, F. Chmelik, Kovove Mater. 47, 1 (2009).

[8] A.M. Galiyev, R.O. Kaibyshev, G. Gottstein, in: Magnesium Technology 2002, Ed. H.I. Kaplan, TMS (The Minerals, Metals \& Materials Society), Warrendale, PA, USA 2002, p. 181.

[9] G.M. Xie, Z.Y. Ma, L. Geng, Mater. Sci. Eng. A 486 , 49 (2008).

[10] M. Shahzad, D. Eliezer, W. Gan, S.B. Yi, L. Wagner, Mater. Sci. Forum 561-565, 187 (2007).

[11] M. Shahzad, M. Janecek, L. Wagner, Int. J. Mater. Res. 100, 370 (2009).

[12] M.Z. Oo, J. Mueller, M. Janecek, L. Wagner, Int. J. Mater. Res. 100, 374 (2009). 